\title{
Improvement of Industrial Cabinet-Installed Electronic Equipment Resilience to HEMP Impact
}

\author{
Vladimir Gurevich, Ph.D. \\ Central Electrical Laboratory Israel Electric Corp., Haifa, Israel
}

*Corresponding Author: Vladimir Gurevich, Central Electrical Laboratory Israel Electric Corp., Haifa, Israel

\begin{abstract}
Modern power systems employ a lot of sophisticated electronic equipment and largely depend on its functionality. At the same time, highly sensitive electronic equipment is particularly responsible for deterioration of the power system's resilience to HEMP. This article discusses practical measures aimed at improvement of cabinet-installed electronic equipment to EMP at power industry facilities. Information and recommendations suggested in the article will benefit both newly designed and existing power facilities at rather affordable costs.
\end{abstract}

Keywords: HEMP, susceptibility of electronic equipment, protected control cabinets, ferrite filters, protection from EMP

\section{INTRODUCTION}

There are hundreds of types of sophisticated electronic equipment adopted by power plants and substations. These include: digital protection relays (DPR), automation, telecommunication and communication devices, which ensure functionality of the modern electric power industry. These types of equipment are designed based on microelectronic and microprocessor-based devices, which are very sensitive to external electromagnetic impacts. This is especially true for powerful and devastating High Altitude Electromagnetic Pulse (HEMP), which creates a pulse of electric field with a strength of up to $50 \mathrm{kV} / \mathrm{m}$ at the ground surface. Due to expanded use of microelectronic and microprocessor-based equipment in the electric power industry (while this is the core of infrastructure of any country of the world), its susceptibility to HEMP is also rising. This is also appreciated by military men, who improve the methods of non-nuclear EMP creation, as well as to try to increase the EMP component during high altitude (30-400 km) nuclear explosion (so called "super-EMP"). Blasting of nuclear ammunition at this altitude does not directly affect the public. However, it can cause the country's infrastructure to be inoperable for a long time, and consequently it is very attractive to military men. Thus, development of methods and techniques to protect sensitive electronic equipment from HEMP becomes very relevant.

\section{NEW CABINETS FOR ELECTRONIC EQUIPMENT}

Previously, electromechanical protection relays of old power plants and substations were mounted on special panels facing personnel and featuring an open back side, where the circuits were connected

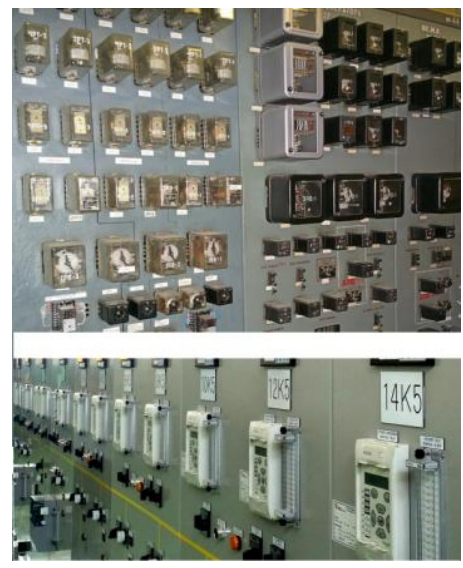

Figure1. Relay protection panels: electromechanical (above) and microprocessor-based (below). 
(Fig1). Upon transition to digital protection relays (DPR), this principle was initially kept. The same principle was used to mount other types of electronic equipment. However, sometime later another principle of mounting was introduced: electronic equipment was mounted in special cabinets. Today, this principle of electronic equipment installation is deemed the most promising, convenient and justified. Nowadays, a typical relay room of a power plant or a substation accommodates several rows of clean and beautiful cabinets.

However, the problem is that this beauty conceals the lack of functionality as the beautiful cabinets with glass doors (Fig.2) do not provide protection of inside the electronic equipment from electromagnetic impact, though the idea of a closed cabinet envisages protection of internal space from adverse external impact.

At the same time there are many specially designed metal cabinets (Fig. 3), ensuring significant weakening of electromagnetic emission.

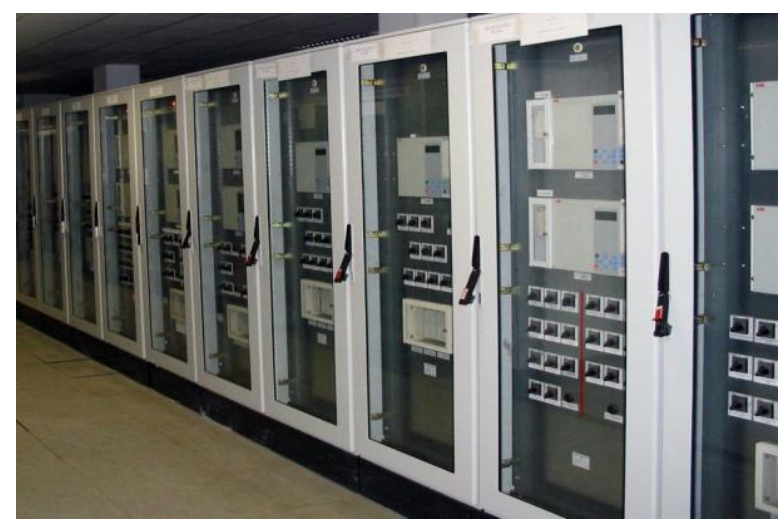

Figure 2. Contemporary way of electronic equipment mounting in cabinets

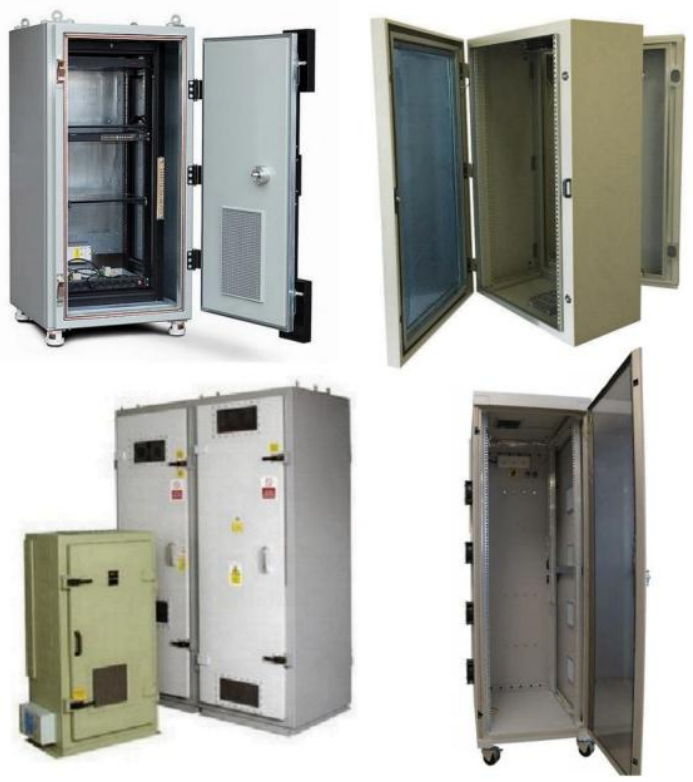

Figure3. Specially designed metal cabinets ensuring significant weakening of electromagnetic emission.

Standard cabinets made of sheet steel, containing no windows or cracks, significantly reduce the electromagnetic pulse. However, use of galvanized mounting panels are used to produce the cabinets, as well as special conductive sealers and gaskets, which result in significant improvement of their efficiency, since zinc priming allows to level up the potentials on a large area (electrical resistivity of steel is $0.103-0.204 \mathrm{Ohm} \times \mathrm{mm}^{2} / \mathrm{m}$, while electrical resistivity of zinc is $0.053-0.062 \mathrm{Ohm} \mathrm{x} \mathrm{mm} / \mathrm{m}$ ). Aluminum has even lower resistance $(0.028 \mathrm{Ohm} \mathrm{x} \mathrm{mm} / \mathrm{m})$. That is why some companies produce all-in-one cabinets made of special Aluzinc-150 alloy (Aluzinc ${ }^{\circledR}$ is a registered trade mark of Arcelor Group of companies). This steel has a special covering, which consists of 55\% aluminum, $43.4 \%$ zinc and $1.6 \%$ silica. The surface of the cabinet containing this covering provides high level of reflectance 
of electromagnetic radiance wave. Sarel company (now - Schneider Electric Ltd., Great Britain) manufactures and supplies such cabinets to many countries of the world. Other companies also manufacture similar cabinets which ensure HEMP protection. The list of these companies includes: R.F. Installations, Universal Shielding, Eldon, Equipto Electronics, ATOS, MFB, European EMC Products, Amco Engineering, Addison, Line Technics, Efore, Raymond EMC, ETS-Lindgren, Delancer Shielding, Holland Shielding Systems, Trusted Systems, and many others. These cabinets usually ensure 80-90 dB weakening of emission at $100 \mathrm{kHz}-1 \mathrm{GHz}$ frequencies. Many of these cabinets are rather expensive, large and heavy (Fig. 3). They are more suitable to protect military equipment rather than civil facilities. However, multiple protected control cabinets produced by Schneider Electric are rather acceptable and (regardless of their simplicity and affordability) feature fairly good specifications (Fig. 4).
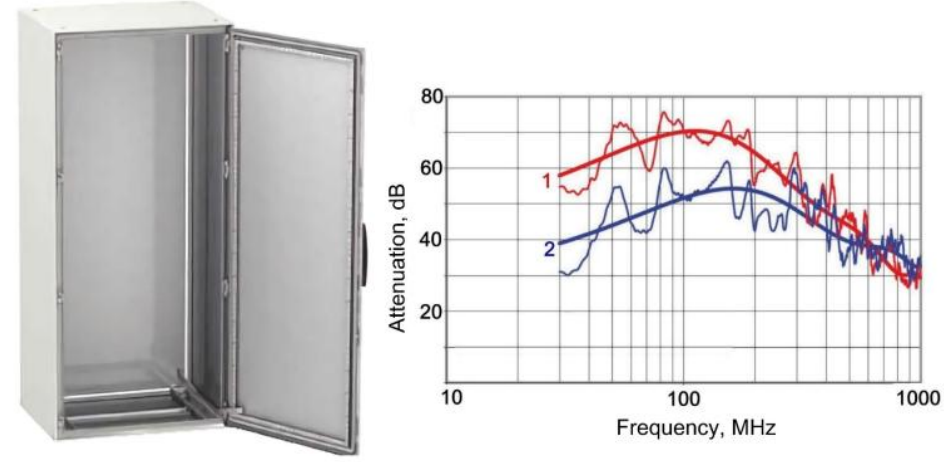

Figure4. Schneider Electric's simple protected control cabinet made of Aluzinc ${ }^{\circledR}$ alloy and its specifications: 1 - weakening of vertical component of electromagnetic field; 2 - weakening of horizontal component.

\section{UPGRADING OF EXISTING CABINETS WITH GLASS DOORS}

The above mentioned guidelines on how to use special control cabinets are applicable to new installations only. They cannot be used for existing substations with unprotected control cabinets. So, how do we proceed? Luckily, there are all the necessary materials in the market which can significantly improve the level of protection of existing control cabinets without the need to substitute them.

Firstly, the door glass should be made impermeable for electromagnetic emission. There are several ways to do this:

- changing glass to metal in the door;

- changing ordinary glass to conductive glass;

- priming of ordinary glass with special conductive coating.

There is a lot of transparent conductive glass on the market (to be specific, glass with a conductive external layer). The list of manufacturers includes Latech ${ }^{\mathrm{TM}}$, Visiontek Systems, Holland Shielding Systems B.V., Techinstro and many others. This glass is produced by adding special substances to the outer layer of the glass during production. Usually, several types of alloying additives are used: indium tin oxide (ITO), fluorine-doped tin oxide (FTO) and rarely doped zinc oxide. There are also polymer conductive panels based on poluyacetylene, polyaniline, polypyrrole, polythiophen, etc. [1].

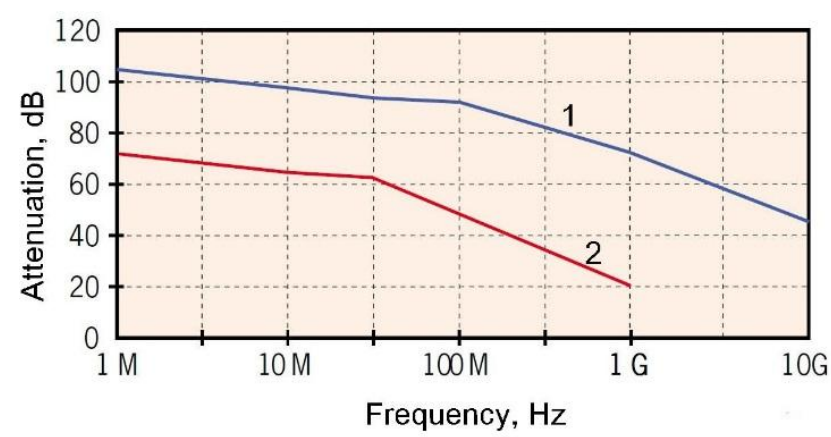

Figure5. Shielding effect of glass with an intermediate copper net layer (1) and glass with conductive outer layer (2)

International Journal of Research Studies in Electrical and Electronics Engineering (IJRSEEE) Page | 26 
The highest shielding effect is provided by 3-layer glass with an internal thin copper net layer produced by Holland Shielding Systems B.V (Fig. 5).

Alternatively, various conductive varnishes, paints, sprays (also readily available on the market) can be used (Fig. 6). These can be easily applied on glass doors.

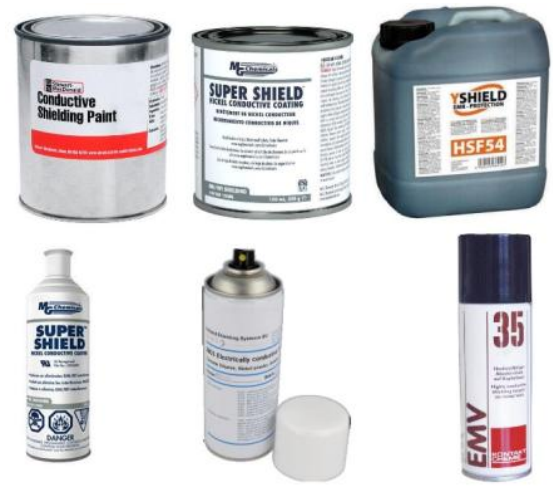

Figure6. Conductive varnishes, paints and sprays.

Additionally, special door seals made of conductive rubber (Fig. 7) can be laid along the doors' perimeter to ensure higher protection of electronic equipment cabinets.
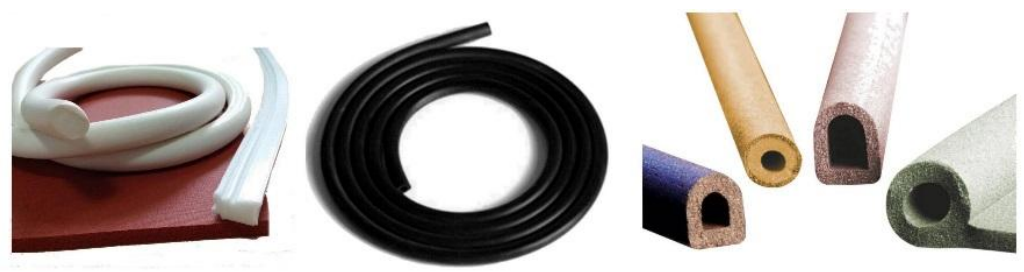

Figure7. Door seals made of conductive rubber

In case there are ventilation blinds in the cabinet, they need to be equipped with special panels (fig. 8) consisting of a dense metal grid or a set of metal tubes with a certain diameter to length ratio (the so called "waveguides-below-cutoff"), which allow air circulation, but prevent an electromagnetic wave from entering the cabinet.
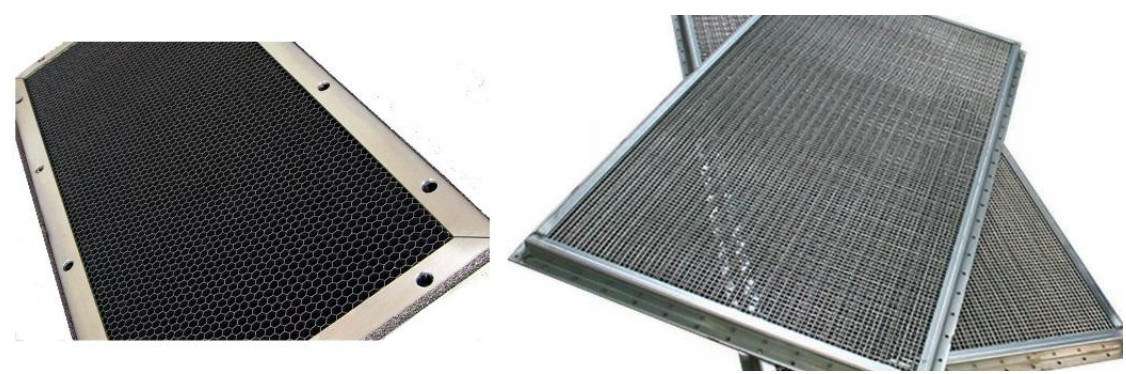

Figure8. Ventilation panels protected from electromagnetic penetration

The honeycomb structure panels (waveguides-below-cutoff), fig. 8 (left) are more preferable as they are less prone to dust accumulation. They are made of round or rectangular (sometimes hexagonal) section pipes welded alongside. Such ventilation panels manufactures by many companies: Huaming Electronic Equipment, Holland Shielding Systems, Chomerics, Kemtron, Parker Chomerics, Solany EMC, Majr Products and other.

It is commonly known that the hollow metal pipe acts as a waveguide that conducts the highfrequency electromagnetic wave. But in order to have this pipe act as a waveguide, it should have specific geometric dimensions that are related to the wave length. If the dimensions of the pipe (waveguide) are different, it can cause significant wave decay (up to 80-100 dB). Specifically, it does not conduct the electromagnetic wave. The waveguides that do not conduct electromagnetic waves at a frequency rate lower than the defined value (also known as the cutoff frequency), are called waveguides-below-cutoff. The size of waveguides-below-cutoff (i.e. the size of pipes used to produce the honeycomb structure panels in our case) is determined using known formulas, Fig. 9. 


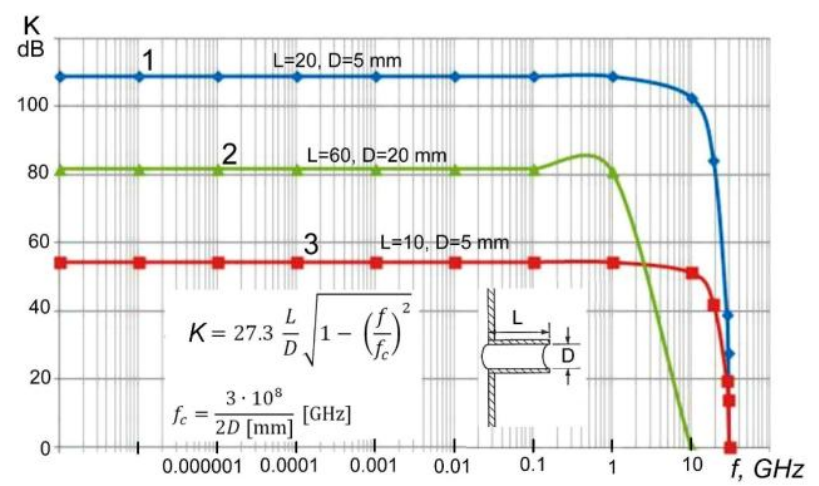

Figure9. Correlation between the index of electromagnetic emission weakening $(K)$ by waveguides-below-cutoff and their geometrical dimensions and frequency. $L$ - length of round section waveguide; $D$ - diameter of the waveguide; $f$-frequency of emission; $f_{C}$ - cutoff frequency.

The curves in Fig. 9 (determined by [2] using these formulas) show that the ability of waveguidesbelow-cutoff to weaken the electromagnetic emissions is maintained in a wide range of frequencies up to the cutoff frequency. In order to ensure the reliable operation of the waveguide-below-cutoff, it is necessary to select this cutoff frequency with a one and a half period margin in relation to maximum working frequency.

Apart from the above mentioned measures, it is advisable to split the inner space of the cabinet into several decks separated by aluminum panels with a minimum number of small openings (cut-outs) for cables.

The methods of improvement of HEMP-resistance described above are fully applicable to cabinets containing power supply equipment, which consist of battery chargers, converters, etc. This kind of equipment is usually placed into cabinets without any doors or those having lots of unprotected ventilation blinds.

\section{UPGRADING OF CABLE INLETS INTO CABINETS}
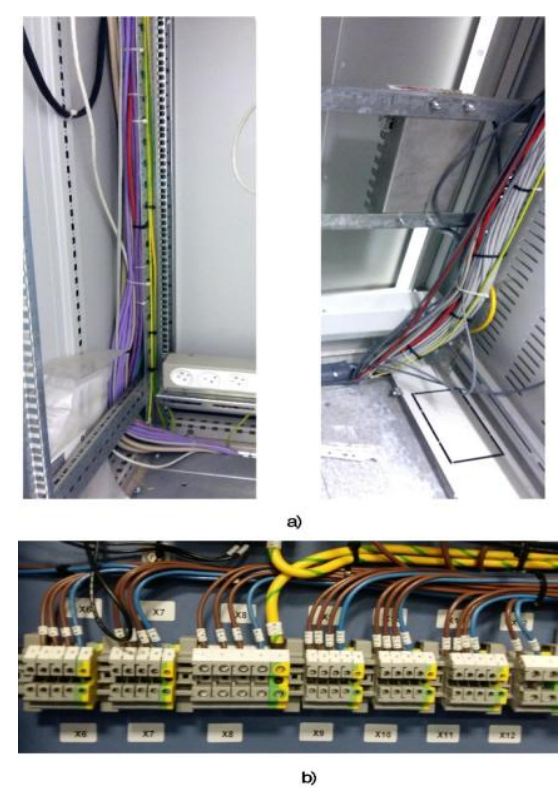

Figure10. There are two main principles of cable entry into a cabinet: a) external cables are laid through the whole cabinet and then they are connected directly to electronic equipment's terminals; b) external cables are connected through intermediate terminals at the cabinet's entrance.

A cabinet protected from electromagnetic emission is a very important, but not an exclusive issue that needs to be addressed in order to protect highly sensitive electronic equipment.

Another problem is represented by multiple control and power cables entering the cabinet. These cables act as antennas absorbing HEMP energy from a large area and delivering it to the interior space of a cabinet and directly to inputs of sensitive electronic equipment. 
Thus, the cables make it necessary to address at least two additional issues: protection of the cabinet's interior space from over-emission from cables entering from outside and their screens (in case they are shielded), as well as protection of electronic equipment inputs. A design of a new power facility can provide for special cabinets, shielded cables, more efficient placement of equipment inside the cabinets and mounting of special protection of this equipment from HEMP. However, in case of existing facilities the situation is much more difficult as it is not possible to change either cabinets or cables. So, let us address this, which is the most difficult situation.

There are two main principles of cable entry (Fig. 10) into control, relay protection and communication cabinets: when external cables are laid through the whole cabinet and then they are connected directly to the electronic equipment's terminals; and when external cables are connected to intermediate terminals at the cabinet's entrance. Cable harnesses entering the cabinets may consist of shielded and unshielded cables; cables delivering high frequency signals and cables delivering analogue DC signals; as well as DC and AC power supply cables. The problem is that it is impossible to use a certain common protection for all cables due to a variety of signals delivered by them. Consequently, the first thing to do is to split a common harness into individual harness groups with similar signals. Then, if we deal with option (a) - see fig. 10 - we need to provide separate shielding for each of the separated groups of external cables laid inside a cabinet. This can be achieved by a detachable flexible screen, containing conductive fabric with a longitudinal zip (produced by Kemtron) or by wrapping separate cable harnesses into conductive tape with adhesive layer (Fig. 11).
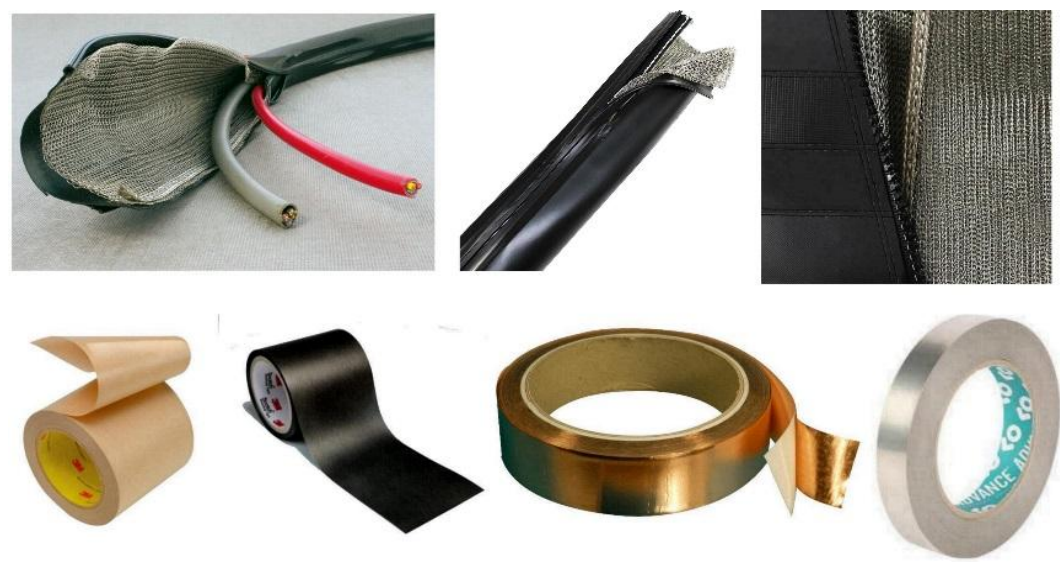

Figure11. Flexible detachable screen with a zip containing conductive fabric (above) and different types of copper, aluminum and graphite conductive tapes with adhesive layer (below).

The openings in the cabinet's bottom (at the cables' entrance) should be tightly sealed with conductive fabric (Fig. 12). If these openings are large, place a metal grid underneath to hold the fabric in place.
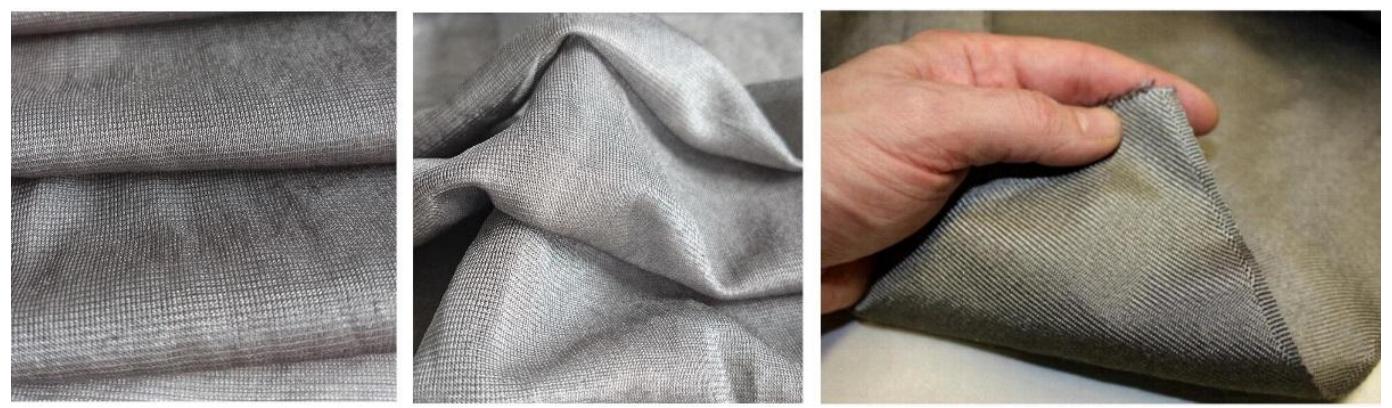

Figure12. Conductive fabric

DC or AC power supply cables are the most problematic from the standpoint of electromagnetic compatibility. Thus, they need to have protection facilities ensuring the highest level of HEMP weakening. This facility includes high-frequency chokes, embedded into positive and negative core (or Live and Neutral), fig. 9, as well as voltage pulse suppressors. The chokes are small and should be located at the cable's entry into the cabinet (i.e. on the cabinet's bottom) underneath the conductive fabric. These chokes (Table 1, fig. 13) have very low DC resistance (milliohm) and high impedance for a short EMP pulse. One choke encapsulated with epoxy compound costs about 100 US Dollars. 

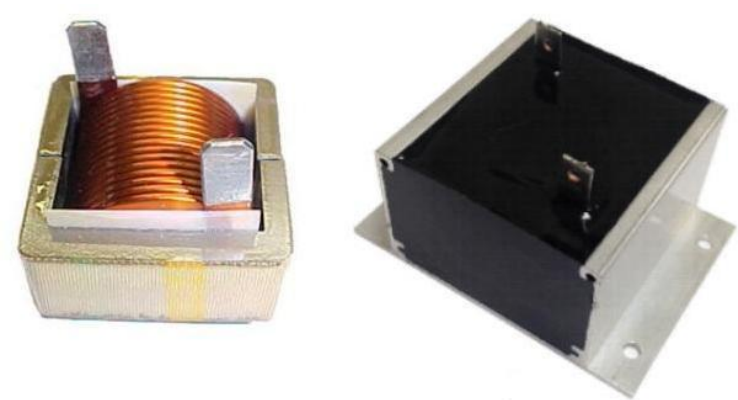

Figure13. Chokes produced by CWS Company with helical type winding and a core made of special alloy to weaken EMP pulse in a power supply cable. Open (left) and encapsulated with epoxy compound (right).

Table1. Main parameters of high frequency choke for supply circuits of cabinets with electronic equipment of supervision, control, relay protection and telecommunication.

\begin{tabular}{|c|c|c|c|c|c|c|}
\hline \multirow[b]{2}{*}{ Type } & \multirow[b]{2}{*}{$\begin{array}{l}\text { Current } \\
\text { Rating, A }\end{array}$} & \multirow{2}{*}{$\begin{array}{l}\text { Inductance at DC } \\
\text { Bias } 40 \mathrm{~A}, \mu \mathrm{H}\end{array}$} & \multicolumn{3}{|c|}{ Impedance } & \multirow[b]{2}{*}{$\begin{array}{l}\text { Dimensions, } \\
\mathrm{mm}\end{array}$} \\
\hline & & & $\mathrm{DC}, \mathrm{m} \Omega$ & $\begin{array}{l}1 \mathrm{MHz} \\
\text { (calculated), } \mathrm{k} \Omega\end{array}$ & $\begin{array}{l}1 \mathrm{GHz} \\
\text { (calculated), } \mathrm{M} \Omega\end{array}$ & \\
\hline $\begin{array}{l}\text { EK55246- } \\
341 \mathrm{M}- \\
40 \mathrm{AH}\end{array}$ & 40 & 162 & 14.5 & 1.0 & 1.0 & $58 \times 58 \times 35$ \\
\hline
\end{tabular}

The chokes' inductance necessary for efficient suppression is measured considering its reduction due to DC flowing through them. This is the reason why special types of chokes (requiring cable cutting) are advisable (fig. 13). For 10b principle of cable entry this will not be a problem, while in 10a principle cable cutting at the cabinet's entry will be required to connect the choke. Nonetheless, since there are only two cores, this is not expected to be a problem for 10a as well.

Portable ferrite filters that do not require cutting of cables (Fig. 14) can successfully be used for other groups of cables with low frequency signals (in the range of up to several kilohertz) and with analogue DC signals (4-20 mA); with low currents of industrial frequency; with logic signals of relay protection.

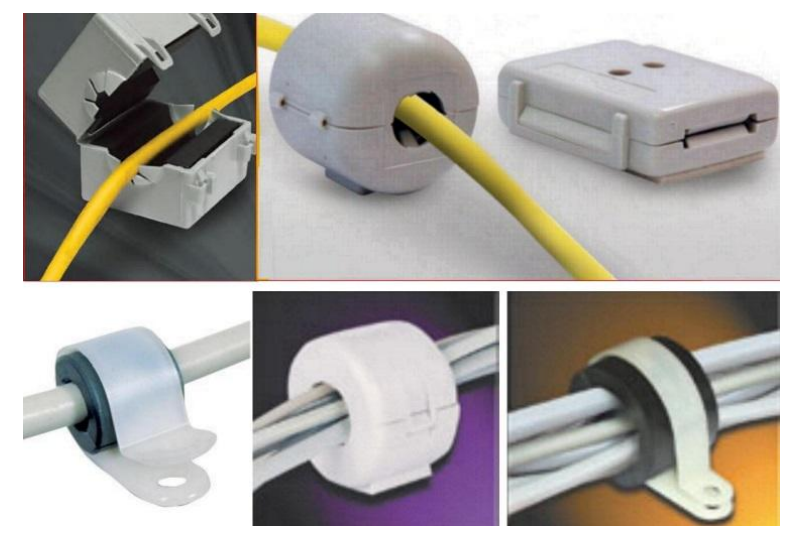

Figure14. Portable ferrite filters that do not require cutting of cables

Table2. Specifications of ferrite filters with maximum internal diameter to be mounted on control cables entering protected cabinets.

\begin{tabular}{|l|l|l|l|l|l|l|}
\hline \multirow{2}{*}{ Catalog Number } & \multirow{2}{*}{ Filter Kind } & $\begin{array}{l}\text { Cable } \\
\text { Diameter } \\
\text { Maximal, } \\
\text { mm }\end{array}$ & $\begin{array}{l}\text { Frequency Range, } \\
\text { MHz }\end{array}$ & $\begin{array}{l}\text { Minimal } \\
\text { Impedance, } \\
\Omega\end{array}$ & $\begin{array}{l}\text { Maximal } \\
\text { Impedance, } \\
\Omega\end{array}$ & $\begin{array}{l}\text { Cost, } \\
\text { USD }\end{array}$ \\
\hline \multicolumn{7}{|c|}{ Fair-Rite Corp. } \\
\hline 0475176451 & \multirow{2}{*}{$\begin{array}{l}\text { Round Cable } \\
\text { Snap }\end{array}$} & 18 & $0.2-5.0$ & 30 & 130 & 17 \\
\cline { 4 - 8 } & 18 & $1-300$ & 47 & 380 & 8 \\
\cline { 3 - 8 } & 18 & $100-1000$ & 110 & 480 & 9 \\
\cline { 3 - 8 } & Assembly & 25 & $1-250$ & 45 & 375 & 13 \\
\hline 046117645451 & $\begin{array}{l}\text { Split Round } \\
\text { Cable Core }\end{array}$ & 35 & $1-300$ & 60 & 530 & 13 \\
\hline 2631181381 & &
\end{tabular}

International Journal of Research Studies in Electrical and Electronics Engineering (IJRSEEE) Page 30 


\begin{tabular}{|l|l|l|l|l|l|l|}
\hline \multicolumn{9}{|c|}{ Wurth Elektronik } \\
\hline 74271251 & $\begin{array}{l}\text { Round Cable } \\
\text { Snap } \\
\text { Assembly }\end{array}$ & 25 & $10-1000$ & 110 & 160 & 31 \\
\hline & \multicolumn{7}{|l|}{ Laird } \\
\hline $\begin{array}{l}\text { LFB360230- } \\
300\end{array}$ & $\begin{array}{l}\text { Non-Split } \\
\text { Round Cable }\end{array}$ & 23 & $0.5-5$ & 24 & 19 & 4 \\
\cline { 3 - 8 } 28B1417-200 & 23 & $25-300$ & 52 & 230 & 1.7 \\
\cline { 3 - 8 } & Core & 35.5 & $25-300$ & 60 & 285 & 6 \\
\hline
\end{tabular}

Moreover, these filters should be mounted in those places where cables enter the cabinet. In other words, on its floor and under the conductive fabric. The features of these filters and the methods of their selection have been discussed in [3]. It would be appropriate to remind the reader that this means that three filters with different frequency specifications are put on the same group of cables. These three filters would provide the most efficient weakening of EMP in the required frequency range.

Ferrite filters with required parameters are produced by various companies. Nonetheless, the most appropriate units that ensure cable protection from EMP are those produced by Fair-Rite Corp. and Wurth Elektronik (Table 2), even though they are far from inexpensive. The table above shows data for filters with maximum internal diameter, as using a filter for a group of cores (cables) is the most cost effective. A good example would be a set of three filters of the first type (from Table 2), which provide efficient EMP weakening in the required frequency range, when mounted on each group of cores (cables).

In case the cables are connected as depicted in fig. 10b, it would be much easier if the cores were disconnected from the terminal for the period of ferrite filter mounting (at the cable's entry near the terminal). In this case, inexpensive, non-split ferrite rings and cylinders (Table 2) can be used.

It should be kept in mind that the filters should not be used in low power communication circuits which work in the same frequency range with filters.

\section{Voltage Pulse SuPPRESSing}

Another common problem, which needs to be solved to protect any type of electronic equipment from EMP, is suppressing of the pulse overvoltage at its input terminals. Not all types of non-linear elements used to protect from switching or lightning overvoltage are suitable for HEMP protection, as this pulse is very short and can increase rapidly. The most suitable (in terms of features) are those elements that implement avalanche breakdown of $p$ - $n$ junction in solid-state devices. This is the principle adopted in so-called Transient Voltage Suppressor Diodes (TVS-diodes).

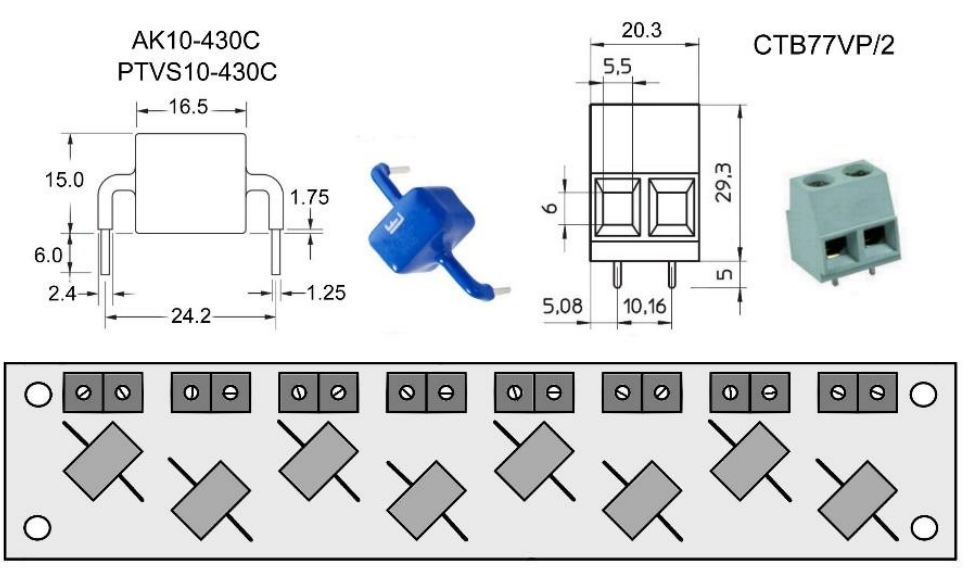

Figure15. Multi-channel voltage pulse suppression device containing TVS-diodes and standard terminals mounted on a small printed circuit board.

Until recently, these elements had some limitations in terms of their power and that is why there were not used in power circuits. Nevertheless, two renowned competing companies - Littelfuse and Bourns - started manufacturing powerful TVS-diodes suitable for this purpose (Table 3). 
Table3. Main parameters of some types of powerful TVS-diodes

\begin{tabular}{|l|l|l|l|l|}
\hline Type & Nominal Voltage, V & $\begin{array}{l}\text { Avalanche Breakdown } \\
\text { Voltage, V }\end{array}$ & Clamping Voltage, V & $\begin{array}{l}\text { Peak Pulse } \\
\text { Current, A }\end{array}$ \\
\hline Littelfuse & \multicolumn{5}{|l|}{} \\
\hline AK10-430C & 430 & $440-490$ & 625 & 10.000 \\
\hline AK6-430C & 430 & $440-490$ & 625 & 6.000 \\
\hline AK3-430C & 430 & $440-490$ & 625 & 3.000 \\
\hline Bourns & $440-490$ & 580 & 10.000 \\
\hline PTVS10-430C & 430 & $440-490$ & 580 & 6.000 \\
\hline PTVS6-430C & 430 & $440-490$ & 580 & 3.000 \\
\hline PTVS3-430C & 430 &
\end{tabular}

Unfortunately, these components are still produced for mounting on printed circuit boards only, rather than separate devices in a plastic body to be mounted in a control cabinet on a standard DIN-rail, with screw connections to connect external cables. But this problem can also be solved by using a simple and small plate with printed wiring (Fig. 15). Recommended types of TVS-diodes: AK10-430C (Littelfuse) or PTVS10-430C (Bourns) to protect AC and DC power supply circuits 230-250 V and TVS-diodes: AK3-430C (Littelfuse) and PTVS3-430C (Bourns), to protect supervision and control circuits, as well as logic DPR inputs operating at $250 \mathrm{~V}$. These elements are not inexpensive (about 120 USD for the first group and about 50 USD for the second), so they should only be used to protect critical types of equipment located at critical facilities of the electric power industry.

In order to protect the cabinet's equipment mounted as shown in Fig.10b, the printed circuit board with TVS-diodes needs to be installed near the input terminal, whereas the outputs of the diodes should be connected by means of the shortest possible conductors to terminals parallel to input cores of cables of the same circuits (differential mode).

In order to protect the cabinet's equipment mounted as shown in figure 10a, the printed circuit board with TVS-diodes needs to be installed near the input terminals of the internal equipment and connected to them following the same principle. Moreover, long input cables running through the cabinet must be shielded by means shown in Fig. 11.

Unfortunately, the described powerful TVS-diodes cannot be used to protect telecommunication equipment located in the same cabinets due to high capacitance of their $p$ - $n$-junctions. Indeed, connection of these diodes into low power high frequency circuits of telecommunication systems can result in their malfunctioning and thus it is unacceptable. To address this issue, a protection device has been designed (Fig. 16), which employs other elements (Table 4, Fig. 17 [4]).

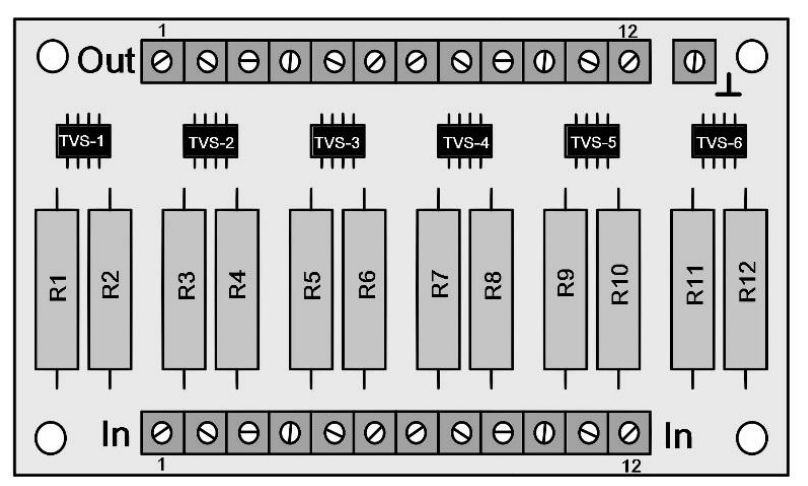

Figure16. Protection device for low voltage high frequency circuits of telecommunication equipment.

Table4. Main parameters of SP03-6 transient voltage suppressor.

\begin{tabular}{|l|l|}
\hline Max. Stand-Off Voltage, V & 6 \\
\hline Min. Avalanche Breakdown Voltage, V & 6.8 \\
\hline Max. Leakage Current, $\mu \mathrm{A}$ & 25 \\
\hline Max. Clamping Voltage, V & 20 \\
\hline Peak Pulse Current $(8 / 20 \mu \mathrm{s}), \mathrm{A}$ & 150 \\
\hline Peak Pulse Power $(8 / 20 \mu \mathrm{s}), \mathrm{W}$ & 2800 \\
\hline Max. Junction Capacitance, pF & 25 \\
\hline
\end{tabular}




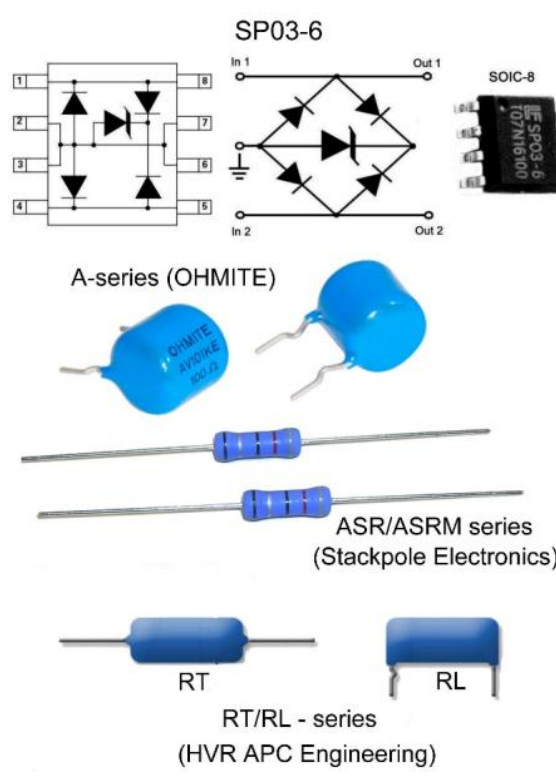

Figure17. Components used in the protection device for telecommunication systems: Above - Transient voltage suppressor, type SP03-6 (Table 3), below - high voltage low-resistance anti-surge resistors of various types, see their parameters in Table 5.

Table5. Main parameters of some types of high voltage anti-surge resistors

\begin{tabular}{|l|l|l|l|}
\hline Type & Manufacturer & $\begin{array}{l}\text { Max. Pulse Voltage and } \\
\text { Power }\end{array}$ & Dimensions, mm \\
\hline ASRM2 & Stackpole Electronics & $5 \mathrm{kV} ; 2 \mathrm{~W}$ & Dia. $=5 ; \mathrm{L}=15$ \\
\hline PPR200 & Firstohm & $20 \mathrm{kV} ; 2 \mathrm{~W}$ & Dia. $=5 ; \mathrm{L}=13.5$ \\
\hline RT/RL & HVR ARC Engineering & $7.5 \mathrm{kV} ; 2 \mathrm{~W}$ & Dia. $=8 ; \mathrm{L}=18$ \\
\hline AZ & Ohmite & $2.5 \mathrm{kV} ; 2 \mathrm{~W}$ & Dia. $=26 ; \mathrm{L}=30$ \\
\hline SPO250 & HVR International & $5.7 \mathrm{kV} ; 2 \mathrm{~W}$ & Dia. $=13 ; \mathrm{L}=15$ \\
\hline
\end{tabular}

This device is connected parallel to inputs of telecommunication equipment being protected and features relatively low price (about 3 USD for a suppressor and about 2 USD for a resistor).

\section{RETrofit OF The Grounding SySTEM OF EleCtric CABINETS}

The issues of a conventional grounding system of electronic equipment mounted in electric cabinets and specifications of its grounding under HEMP impact has been addressed in [5] in full details. Herewith, it is reminded that a conventional grounding system does not provide HEMP protection, but rather acts as a source of dangerous pulse impacts onto the electronic equipment. For this reason, it should be designed as stipulated in recommendations suggested in [6].

\section{CONCLUSION}

Information and specific recommendations suggested in this article, as well as technical data of elements and materials, allow developers and engineers to design power facilities with electronic equipment protected from HEMP. It also allows to upgrade and retrofit existing equipment and incur affordable costs, and thus, significantly improve the level of power facilities' protection from HEMP.

\section{REFERENCES}

[1] Skotheim, Terje A. Reynold, John - Handbook of Conducting Polymers, CRC Press, 1998.

[2] Ivko A. Screening of Radio-Electronic Equipment as Means of Electromagnetic Compatibility Implementations. - The Modern Electronics, 2015, No. 8, pp. 86 - 90 (by Russian).

[3] Gurevich V. The Problems of Correct Choice of Ferrite Beads. - Electrical Engineering and Electromechanics, 2016, No. 2, pp. $71-73$.

[4] Gurevich V. Protection of Telecommunication Systems in Electric Power Facilities from Electromagnetic Pulse (EMP). - An International Journal of Advanced Computer Technology, 2017, No. 6, Vol. VI, Issue IX, pp. $2446-2450$.

[5] Gurevich V. Is the Electric Equipment Grounding the Basic Protection Means Against HEMP? International Journal of Research Studies in Electrical and Electronics Engineering, 2018, Vol. 4, Issue 1, pp. $1-8$.

International Journal of Research Studies in Electrical and Electronics Engineering (IJRSEEE) Page | 33 
[6] Gurevich V. The Issues of Electronic Equipment Grounding at the Power Facilities. - International Journal of Research Studies in Electrical and Electronics Engineering, 2017, Vol. 3, Issue 1, pp. 11 - 19.

\section{AUTHOR'S BIOGRAPHY}

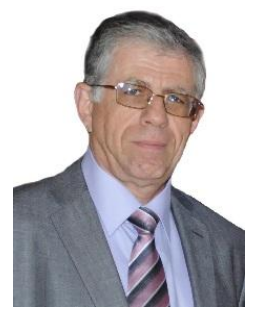

Vladimir I. Gurevich was born in Kharkov, Ukraine, in 1956. He received an M.S.E.E. degree (1978) at the Kharkov Technical University, named after P. Vasilenko, and a Ph.D. degree (1986) at Kharkov National Polytechnic University.

His employment experience includes: teacher, assistant professor and associate professor at Kharkov Technical University, and chief engineer and director of Inventor, Ltd.

In 1994, he arrived in Israel and works today at Israel Electric Corp. as a Senior specialist and Head of section of the Central Electric Laboratory.

He is the author of more than 200 professional papers and 13 books and holder of nearly 120 patents in the field of electrical engineering and power electronics. In 2006 he was Honorable Professor with the Kharkov Technical University.

Citation: Vladimir Gurevich. "Improvement of Industrial Cabinet-Installed Electronic Equipment Resilience to HEMP Impact”, International Journal of Research Studies in Electrical and Electronics Engineering, 4(1), pp 24-34. DOI: http://dx.doi. org/10.20431/2454-9436.0401003

Copyright: (C) 2018 Vladimir Gurevich. This is an open-access article distributed under the terms of the Creative Commons Attribution License, which permits unrestricted use, distribution, and reproduction in any medium, provided the original author and source are credited. 